\title{
The Impact of Servant Leadership on Proactive Behaviors: A Study Based on Cognitive Evaluation Theory
}

\author{
Jing Luo, Jiabin Zheng \\ South China University of Technology, Guangzhou, China \\ Email: bmli1106@foxmail.com
}

How to cite this paper: Luo, J., \& Zheng, J. B. (2018). The Impact of Servant Leadership on Proactive Behaviors: A Study Based on Cognitive Evaluation Theory. Psychology, 9, 1228-1244.

https://doi.org/10.4236/psych.2018.95075

Received: April 4, 2018

Accepted: May 28, 2018

Published: May 31, 2018

Copyright $\odot 2018$ by authors and Scientific Research Publishing Inc. This work is licensed under the Creative Commons Attribution International License (CC BY 4.0).

http://creativecommons.org/licenses/by/4.0/

\begin{abstract}
The purpose of this study is to examine the relationship between servant leadership and proactive behaviors. Apart from this, drawing on the cognitive evaluation theory, we regard that proactive behaviors are driven by intrinsic motivation and further propose three psychological constructs to clarify the underlying mechanisms of servant leadership on employees' proactive behaviors: Job autonomy, leader-member exchange and role breadth self-efficacy. Using a sample of 227 leader-employee dyads from two companies, the empirical results show that: 1) Servant leadership had positive effects on individual task proactivity and team member proactivity; 2) The relationship between servant leadership and individual task proactivity was mediated by job autonomy and role breadth self-efficacy, while leader-member exchange and role breadth self-efficacy mediated the influence of servant leadership on team member proactivity. All hypotheses were supported. Overall, this study enriches and develops related theories of proactive behaviors' influencing factors. It uses cognitive evaluation theory to integrate the mechanisms that motivate employees' proactive behaviors. It species the different psychological processes that servant leadership promotes employees' proactive behaviors directed to different targets. It provides important references for managers to effectively encourage employees' individual task proactivity and team member proactivity. Besides, limitations and suggestions for future research are discussed at the end of the article.
\end{abstract}

\section{Keywords}

Proactive Behavior, Servant Leadership, Job Autonomy, Leader-Member Exchange, Role Breadth Self-Efficacy 


\section{Introduction}

Due to the increasing dynamics and uncertainty in external business environment, the flat and decentralized tendency of internal organization construction, and the emergence of self-management teams, to show more proactive behaviors is increasingly important for employees. Proactive behavior involves self-initiated efforts to bring about change in the work environment and/or oneself to achieve a different future; it has three key attributes: Self-starting, change oriented, and future focused (Parker, Bindl, \& Strauss, 2010).

Previous studies have explored how to effectively motivate employees' proactive behaviors from the perspectives of individual and context. As an important part of the organizational context, leadership's influence on employees' proactive behaviors has received much research attention. Although previous studies have examined the impact of some leadership factors, such as transformational leadership, ethical leadership, leaders' supportive and empowered behaviors on proactive behaviors, the servant leadership which combines service, altruism, empowerment, and ethics with the natural fit of proactive behaviors has not been tested by empirical research. There are many contextual variables that affect proactive behaviors of employees, as a result, a single behavior or style of leadership can't stimulate employees well. Only when they are organically integrated into a multi-faceted leadership that interacts and promotes each other, can employees' proactive behaviors be influenced strongly. Servant leadership is exactly such a multiple leadership which contains seven dimensions: conceptual skills, empowerment, helping subordinates grow and succeed, putting subordinates first, behaving ethically, emotional healing, creating value for the community (Liden, Wayne, Zhao, \& Henderson, 2008).

Therefore, the purpose of this study is to examine the relationship between servant leadership and proactive behaviors. Apart from this, drawing on the cognitive evaluation theory, we regard that proactive behaviors are driven by intrinsic motivation and further propose three psychological constructs to clarify the underlying mechanisms of servant leadership on employees' proactive behaviors: job autonomy, leader-member exchange and role breadth self-efficacy. Besides, according to the research of Griffin et al. (2007), we divide proactive behaviors into individual task proactivity and team member proactivity. Different-directed proactive behaviors require employees to assume different degree of risk, and the psychological needs to focus on satisfying are also different, finally resulting in variation in their generating mechanisms. Comparison of individual task proactivity and team member proactivity will further deepen people's understanding of employees' proactive behaviors and implicate leaders to treat them differently in order to effectively encourage employees' individual task proactivity and team member proactivity.

\section{Theoretical Development and Hypotheses}

\subsection{Servant Leadership and Proactive Behavior}

The servant-leader is a steward who holds the organization in trust to the public 
it serves, while remaining intimately attuned to the needs and situations of those who work in the organization and sincerely committed to empowering others to succeed professionally and personally (Reinke, 2004). According to the study of Parker et al. (2010), antecedent variables such as leadership can motivate employees' "can do", "reason to" and "energized to" motivational states that prompt proactive goals' generation and sustain goalsstriving. And many features of servant leadership can well impel these three motivational states of employees.

Can do motivation arises from perceptions of self-efficacy, control, and (low) cost (Parker, Bindl, \& Strauss, 2010). And servant leadership can impel can do motivation, reasons are as follow: Firstly, servant leadership attaches great importance to the career development of employees and provides space and opportunities for the growth of employees. This provides adequate guarantee for the accumulation of employees' abilities and the improvement of their competency, making them feel capable of challenging harder task in their own work even the entire team. Secondly, servant leadership encourages employees to participate in team decision-making, so employees have the opportunity to know about the work flow, progress and goals of the entire team which can enhance the employees' overall control ability of team affairs and help employees to make contribute to team's better development. Thirdly, servant leadership actively supports employees during their work, and provides help when employees encounter difficulties, which can enhance the feasibility perception and reduce the risk perception for employees' proactive behaviors, thus leading to more confidence in completing challenging proactive behaviors.

Reason to motivation relates to why someone is proactive, including reasons flowing from intrinsic, integrated, and identified motivation (Parker, Bindl, \& Strauss, 2010). And servant leadership can impel reason to motivation, reasons are as follow: Firstly, servant leadership is willing to authorize and encourages employees to handle important work decisions by their own. This helps employees to have a high sense of responsibility for their own work that encourages them to initiate better ways of doing their core tasks and promotes the generation of individual task proactivity. Secondly, servant leadership strives to reach consensus on important decision among employees in the team. This helps to stimulate employees' sense of responsibility for collective affairs and turn the goals of team into their own goals instead of negatively thinking that "it is not my job" (Parker, Wall, \& Jackson, 1997), which prompts them to work hard to improve team performance, resulting in team member proactivity. Thirdly, servant leadership regards leader's position as opportunities for serving employees. With a strong altruistic spirit and high ethical standard, he/she puts the interests of employees and organization ahead of his/her own, he/she emphasizes the importance of giving back to groups and encourages everyone to promote collectivism in workplace. All of these have formed a demonstration and infection for employees, encouraging employees to take leader as a model and energetically make contribution to the development of the team, finally enhancing employees' willingness of team member proactivity. 
Energized to motivation refers to activated positive affective states that prompt proactive goal regulation (Parker, Bindl, \& Strauss, 2010). Positive affect can help individuals to think more flexibly and optimistically, so that they can have more positive awareness and good outcome expectations for challenging, long-term, and risky proactive behaviors. Positive affect promotes the setting of more challenging goals (Ilies \& Judge, 2005) and helps individuals engage with a more problematic future (Oettingen, Mayer, Thorpe, Janetzke, \& Lorenz, 2005). In addition, Bindl and Parker (2009) discovered that positive affect can motivate individuals' enterprising spirit and promote individuals to make sustained efforts in the face of difficulties and risks, so as to better achieve their initiative goals. And servant leadership can impel positive affect, reasons are as follow: Firstly, servant leadership is willing to establish friendly relationship with employees. The high-quality relationship with leader is conducive to enhancing employees' self-confidence and promoting positive affect. It also reduces employees' risk perception and produces good results expectation for proactive behaviors which can facilitate the generation of the high-risk team member proactivity. Secondly, servant leadership has strong emotional healing skills. He/she cares about employees and shows sensitivity to others' personal concerns; $\mathrm{He} / \mathrm{she}$ can help employees to get rid of bad emotion. All of those can help employees to maintain positive emotion and high motivation which lays the foundation for individual task proactivity and team member proactivity.

The above arguments taken together, two hypotheses can be generated:

Hypothesis 1: Servant leadership has positive effects on individual task proactivity.

Hypothesis 2: Servant leadership has positive effects on team member proactivity.

\subsection{Intrinsic Driving of Proactive Behavior}

Cognitive evaluation theory points out that individuals' performing of certain behaviors are driven by extrinsic motivation or intrinsic motivation. Extrinsic motivation means that an individual performs a certain behavior because of the external results such as money or honor brought by the behaviors, which has strong control feeling. While intrinsic motivation means that an individual performs a certain behavior because of the sense of accomplishment and satisfaction brought by the behavior itself and represents a state of high autonomy and self-determination. Proactive behavior involves self-initiated efforts to bring about change in the work environment and/or oneself to achieve a different future (Parker, Bindl, \& Strauss, 2010). It is obvious that proactive behavior is a self-driven and highly autonomous behavior. Therefore, it is desirable to regard proactive behavior as an intrinsic motivation-driven behavior based on cognitive evaluation theory.

How can we stimulate the individual's intrinsic motivation and thus generate proactive behaviors? Cognitive evaluation theory maintains that an understand- 
ing of human motivation requires a consideration of innate psychological needs for competence, autonomy, and relatedness (Deci \& Ryan, 2000). And social contexts and individual differences that support satisfaction of the psychological needs for competence, autonomy, and relatedness facilitate natural growth processes including intrinsically motivated behavior and integration of extrinsic motivations (Deci \& Ryan, 2000). Based on the psychological needs for competence, autonomy, and relatedness, we propose three mediating variables: job autonomy (affecting employees' needs for autonomy), leadership-member exchange (affecting employees' needs for relatedness), role breadth self-efficacy (affecting employees' needs for competence), to explore the generating mechanisms of proactive behaviors.

1) Mediating Effects of Job Autonomy

Based on cognitive evaluation theory, needs for autonomy mean that individuals can make free choices for their behaviors without being controlled by others. While job autonomy refers to the degree to which the job provides substantial freedom, independence, and discretion to the individual in scheduling the work and in determining the procedures to be used in carrying it out (Hackman \& Oldham, 1976). It is obvious that the higher the job autonomy is, the more it is able to satisfy individuals' needs for autonomy. Besides, individual task proactivity is defined as the extent to which an individual engages in self-starting, future-oriented behavior to change their individual work situation, their individual work role, or themselves (Griffin, Neal, \& Parker, 2007). While job autonomy mainly reflects the degree of freedom in individual's own work. Therefore, this study mainly discusses the mediating effects of job autonomy on the relationship between servant leadership and individual task proactivity.

From the perspective of the job autonomy's generating mechanisms, the research of Salancik and Pfeffer (1978) pointed out that leadership can affect job autonomy. Servant leadership is willing to authorize and encourage employees to handle important work decisions by their own. Such leadership has greatly increased the employees' discretion in their work, allowing them to freely arrange and determine their own affairs at work, thereby enhancing their job autonomy. In addition, studies also showed that leader's trust in subordinate also positively promotes job autonomy, while servant leadership is exactly a style of leadership that highly trusts employees. Therefore, this study believes that servant leadership is conducive to improving job autonomy.

From the perspective of the job autonomy's effecting mechanisms, the research of Salanova and Schaufeli (2008) found that having job control rights and job autonomy will increase the level of employees' job input and thus promote their proactive behaviors. Apart from this, the research of Hackman and Oldham (1976) pointed out that when employees have a high degree of discretion in their work, they will realize that the results of their work are highly correlated with their own. This will inspire employees' sense of ownership and generate a strong sense of responsibility and achievement. This helps to arouse the individuals' interest in the work itself and motivate employees to pursue higher 
goals, so as to take the initiative to improve the status quo of their work, which is conducive to stimulating individual task proactivity.

As mentioned above, we propose the following hypothesis:

Hypothesis 3: Job autonomy mediates the relationship between servant leadership and individual task proactivity.

2) Mediating Effects of Leader-Member Exchange

Based on cognitive evaluation theory, needs for relatedness mean that individuals want to receive care, support, and understanding from the surrounding environment or others, and establish a relationship of mutual dependence, respect, and trust. The research of Ryan \& Deci (2000) found that safe relationship perception facilitates the development of intrinsic motivation. While the quality of leadership-member exchange reflects the relationship state between leaders and employees (Dienesch \& Liden, 1986), employees can receive care, support, understanding, respect, and trust from high-quality leadership-member exchange. Therefore, the higher the quality of leadership-member exchange is, the more it can satisfy the needs for relatedness. Besides, team member proactivity reflects the extent to which an individual engages in self-starting, future-directed behavior to change their team situation or the way the team works (Griffin, Neal, \& Parker, 2007). It can be seen that the team member proactivity has exceeded employees' scope of work and involves changing the working methods and processes of the entire team. Therefore, it is particularly necessary to gain the understanding and support of the team leader. Therefore, this study mainly discusses the mediating effects of leadership-member exchange on the relationship between servant leadership and team member proactivity.

High-quality leader-member exchange is social exchange relationship that represents high level of trust and responsibility (Graen \& Uhlbien, 1995). This study believes that servant leadership can promote the formation of high-quality leadership-member exchange. Firstly, servant leadership gives trust and respect to employees. The more trust and respect employees receive from leaders, the more responsibility they feel to group, which leads to the formation of highquality leadership-member exchange relationship. Secondly, many empirical studies have shown that leaders' altruism, empowerment, and ethics are beneficial to the establishment of positive emotions between leaders and employees, leading to the formation of high-quality leadership-member exchange (Walumbwa, Hartnell, \& Oke, 2010). And servant leadership has a strong altruistic spirit and puts the interests of employees and organization ahead of his/her own; $\mathrm{He} /$ she is willing to authorize and gives greater responsibility to employees; $\mathrm{He} / \mathrm{she}$ behaves ethically and interacts openly, fairly, and honestly with others. What's more, service leadership is willing to take time and effort to establish friendly relationship with employees; $\mathrm{He} / \mathrm{she}$ cares about employees and can help employees to get rid of bad emotion by using his/her emotional healing skills. All of those help to build a deep relationship between employees and leaders. Day and Crain (1992) pointed out that the relationship between leaders 
and employees affect the quality of leadership-member exchange, and deep relationship leads to high-quality leadership-member exchange.

On the other hand, many studies have shown that high-quality leader-member exchange can effectively stimulate employees' proactive behavior (Van Dyne, Kamdar, \& Joireman, 2008; Botero \& Dyne, 2009; Chen, Lam, \& Zhong, 2007). Team member proactivity has exceeded employees' scope of work and involves changing the working methods and processes of the entire team, which may incur dissatisfaction from leaders and team members. If the action fails, it will endanger the overall efficiency of the team and even threaten the occupational safety of the individual, and the risks it assumes will increase significantly. While the high-quality leadership-member exchange reflects the high-quality interaction between leaders and employees, which meets employees' needs for relatedness and provides a layer of psychological protection for employees' team member proactivity. Besides, high-quality leadership-member exchange is often accompanied by a sense of responsibility. In order to maintain and develop this high-quality exchange relationship, employees will have a reward-psychology for their leaders in which employees take team's affairs that leaders care about as their own responsibility, finally leading to actively contribute to the development of the team. Apart from this, in a highquality leadership-member exchange relationship, leader can transform employee's motivation from short-term-oriented for individual needs to long-termoriented for collective goals, allowing employee to generate the belief that "the team's business is also my business" and thus may promote employee to generate team member proactivity.

On this basis, the following hypothesis can be generated.

Hypothesis 4: Leader-member exchange mediates the relationship between servant leadership and team member proactivity.

3) Mediating Effects of Role Breadth Self-efficacy

Based on cognitive evaluation theory, needs for competence mean that individuals feel competent for the activities they are engaged in. While role breadth self-efficacy refers to employees' perceived capability of carrying out a broader and more proactive set of work tasks that extend beyond prescribed technical requirements (Parker, 1998). It is known from the concept that role breadth self-efficacy focuses on the behaviors that are more initiative and beyond the prescribed working scope. It is obvious that the higher the role breadth self-efficacy is, the more it is able to satisfy individuals' needs for competent. The satisfaction of needs for competent is necessary for any type of behaviors. Therefore, this study explores the mediating effects of role breadth self-efficacy on the relationship between servant leadership and individual task proactivity along with team member proactivity.

This study believes that servant leadership has a positive effect on role breadth self-efficacy. Firstly, servant leadership is willing to help employees grow and succeed that he/she demonstrates genuine concern for others' career growth and development by providing support and mentoring; He/she encourages em- 
ployees to participate in team decision-making so that employees have the opportunity to know about the work flow, progress and goals of the entire team which can enhance the employees' overall control ability of team affairs. As mentioned above, those provide adequate guarantee for the accumulation of employees' abilities and the improvement of their competency, making them feel capable of challenging harder task in their own work even the entire team, and improving role breadth self-efficacy. Secondly, servant leadership possesses the knowledge of the organization and tasks at hand so as to be in a position to effectively support and assist others (Liden, Wayne, Zhao, \& Henderson, 2008), which can reduce the difficulty and risk perception for employees' proactive behaviors, thus leading to more confidence in completing challenging proactive behaviors. Thirdly, servant leadership encourages employees to promote collectivism in the workplace, which promotes a team culture of help each other and reduces fear of risk when employees perform proactive behaviors that exceed their scope of work. What's more, employees can get help and experience from the team, thus greatly increasing employees' role breadth self-efficacy.

From the perspective of the role breadth self-efficacy's effecting mechanisms, many studies have supported that role breadth self-efficacy have positive effects on employees' proactive behaviors (Parker, 1998). Employees with high role breadth self-efficacy have greater confidence in their ability to control their own work and team-related affairs, they will also have higher expectation for their work results, which will greatly reduce their fear for proactive behaviors and increase their psychological security, promoting them to challenge their own work and even the status quo of the entire team, generating individual task proactivity and team member proactivity.

As mentioned above, two hypotheses can be generated:

Hypothesis 5: Role breadth self-efficacy mediates the relationship between servant leadership and individual task proactivity.

Hypothesis 6: Role breadth self-efficacy mediates the relationship between servant leadership and team member proactivity.

Based on discussions all above, the overall framework of the proposed study is shown in Figure 1:

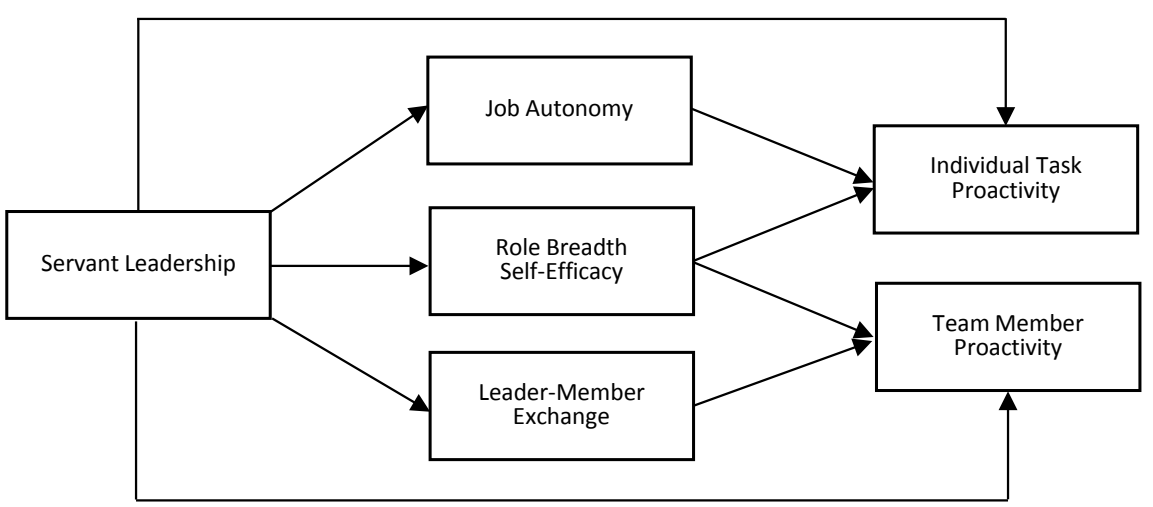

Figure 1. Study model. 


\section{Method}

\subsection{Sample}

Samples were drawn from a state-owned enterprise in Guangzhou city and a private enterprise in Guizhou city. In order to reduce potential common method biases, this study used paired samples of leader-employee dyads. Servant leadership, job autonomy, leader-member exchange, role breadth self-efficacy and employees' demographics were reported by employees, while employees' individual task proactivity and team member proactivity were evaluated by employees' direct leaders.

A total of 280 paired questionnaires of leader-employee dyads were distributed in this survey, and 227 valid questionnaires were actually returned, with an effective rate of $81.1 \%$. Of these employees, $53.7 \%$ were men, $88.1 \%$ were under 30 years old, $85 \%$ held bachelor's degree or above, and $87.2 \%$ were less than 5 years in the current company.

\subsection{Measures}

In order to ensure the scientificity of the research, the scales used in this study were all selected from the articles published in international first-class journals, which had high reliability and validity. Except for the questions assessing demographics, all survey items were measured on 5-point Likert scales ( $1=$ strongly disagree; 5 = strongly agree).

1) Servant leadership was assessed using a 7-item scale developed by Liden et al. (2014). One of the samples reads: "My manager can tell if something work-related is going wrong." The scale showed good reliability with Chinese populations and had a Cronbach alpha coefficient of 0.800 .

2) Job autonomy was assessed using a 3-item scale developed by Hackman and Oldham (1976). One of the samples reads: "I decide how to do my job." The scale showed good reliability with Chinese populations and had a Cronbach alpha coefficient of 0.750 .

3) Leader-member exchange was assessed using a 7-item scale developed by Graen and Uhlbien (1995). One of the samples reads: "I have enough confidence in my leader that I would defend and justify his/her decision if he/she were not present to do so." The scale showed good reliability with Chinese populations and had a Cronbach alpha coefficient of 0.807 .

4) Role breadth self-efficacy was assessed using a 7-item scale developed by Parker (1998). One of the samples reads: "I can analyze a long-term problem to find a solution." The scale showed good reliability with Chinese populations and had a Cronbach alpha coefficient of 0.846 .

5) Individual task proactivity was assessed using a 3-item scale developed by Griffin et al. (2007). One of the samples reads: "he/she would come up with ideas to improve the way in which his/her core tasks are done." The scale showed good reliability with Chinese populations and had a Cronbach alpha coefficient of 0.784 . 
6) Team member proactivity was assessed using a 3-item scale developed by Griffin et al. (2007). One of the samples reads: "he/she would develop new and improved methods to help his/her work unit perform better." The scale showed good reliability with Chinese populations and had a Cronbach alpha coefficient of 0.844 .

7) This study selected four important antecedent variables of proactive behavior in employees' demographics as control variables, they are sex, age, education background, working year in current company.

\section{Results}

\subsection{Test of Common Method Biases}

Although the study used a paired questionnaire form, since the survey data of independent variable and mediator variables were all derived from employees' self-reporting, the impact of common method biases could not be completely eliminated. Therefore, we used Harman single factor analysis to test all the items of servant leadership, job autonomy, leader-member exchange, role breadth self-efficacy. The first principal component obtained without rotation was $34.053 \%$, which was within an acceptable range. Therefore, the common method biases in this study was not serious.

\subsection{Descriptive Statistics and Correlations}

Means, standard deviations and correlations among all key variables are shown in Table 1. As we can see, all correlations were significant. The magnitude and direction of these correlations were consistent with predictions and provided initial support for our hypotheses.

\subsection{Main Effects}

To test hypotheses 1 and 2, we used multiple regression analysis to examine the influence of servant leadership on employees' individual task proactivity and team member proactivity. The regression results of servant leadership with individual task proactivity and team member proactivity are shown in Table 2 . Model 2 estimated that the coefficient on individual task proactivity was positive and significant, providing support for Hypothesis 1. Model 4 estimated that the coefficient on team member proactivity was positive and significant, providing support for Hypothesis 2 .

\subsection{Mediating Effects}

To test hypotheses 3 to 6 , we checked the regression coefficients in order to examine mediating effects of job autonomy, leader-member exchange, role breadth self-efficacy.

According to the results shown in Table 3, when job autonomy was added to model 8, servant leadership's significance of coefficient dropped, which meant job autonomy had a partial mediating effect on the relationship between servant 
leadership and individual task proactivity. In addition, according to the results shown in Table 4, when leader-member exchange was added to model 12, servant leadership's significance of coefficient vanished, which meant leader-member exchange had a full mediating effect on the relationship between servant leadership and team member proactivity. Moreover, according to the results shown in Table 5, when role breadth self-efficacy was added to model 16 and 18, servant leadership's significance of coefficient vanished, which meant role breadth self-efficacy had a full mediating effect on the relationship between servant leadership and individual task proactivity along with team member proactivity.

Table 1. Descriptive statistics and correlations $(\mathrm{N}=227)$.

\begin{tabular}{|c|c|c|c|c|c|c|c|c|}
\hline Variable & M & $\mathrm{SD}$ & SL & JA & LMX & RBSE & ITP & TMP \\
\hline SL & 3.374 & 0.712 & - & & & & & \\
\hline JA & 3.805 & 0.756 & $0.430^{\star * *}$ & - & & & & \\
\hline LMX & 3.494 & 0.606 & $0.728^{\star * *}$ & $0.486^{* * *}$ & - & & & \\
\hline RBSE & 3.531 & 0.678 & $0.399^{\star * *}$ & $0.534^{\star *}$ & $0.570^{* *}$ & - & & \\
\hline ITP & 4.018 & 0.583 & $0.333^{\star * *}$ & $0.489^{\star *}$ & $0.432^{\star *}$ & $0.649^{\star *}$ & - & \\
\hline TMP & 3.668 & 0.781 & $0.295^{\star * *}$ & $0.395^{\star *}$ & $0.386^{\star *}$ & $0.667^{\star *}$ & $0.658^{\star *}$ & - \\
\hline
\end{tabular}

${ }^{*}: p<0.05 ;{ }^{* *}: p<0.01 ;{ }^{* *}: p<0.001 ;$ SL: servant leadership; JA: job autonomy; LMX: leader-member exchange; RBSE: role breadth self-efficacy; ITP: individual task proactivity; TMP: team member proactivity. The same as following tables.

Table 2. Regression analysis of ITP and TMP $(\mathrm{N}=227)$.

\begin{tabular}{|c|c|c|c|c|}
\hline \multirow{2}{*}{ Variable } & \multicolumn{2}{|c|}{ ITP } & \multicolumn{2}{|c|}{ TMP } \\
\hline & Model 1 & Model 2 & Model 3 & Model 4 \\
\hline Sex & 0.021 & 0.021 & 0.012 & 0.012 \\
\hline Age & 0.022 & 0.071 & 0.126 & $0.171^{\star}$ \\
\hline ED & 0.026 & 0.082 & 0.045 & 0.095 \\
\hline WYCC & 0.105 & 0.137 & 0.015 & 0.044 \\
\hline SL & - & $0.374^{\star * *}$ & - & $0.341^{\star * *}$ \\
\hline $\mathrm{R}^{2}$ & 0.014 & 0.146 & 0.019 & 0.129 \\
\hline Adjusted $\mathrm{R}^{2}$ & -0.004 & 0.127 & 0.001 & 0.109 \\
\hline$\Delta \mathrm{R}^{2}$ & 0.014 & 0.133 & 0.019 & 0.110 \\
\hline $\mathrm{F}$ & 0.778 & $7.586^{* * *}$ & 1.052 & $6.523^{* * *}$ \\
\hline$\Delta \mathrm{F}$ & 0.778 & $34.353^{\star * *}$ & 1.052 & $27.899^{\star * *}$ \\
\hline
\end{tabular}

ED: education background; WYCC: working year in current company. The same as following tables. 
Table 3. Mediating effects of JA $(\mathrm{N}=227)$.

\begin{tabular}{ccccc}
\hline \multirow{2}{*}{ Variable } & \multicolumn{2}{c}{ JA } & \multicolumn{2}{c}{ ITP } \\
\cline { 2 - 5 } & Model 5 & Model 6 & Model 7 & Model 8 \\
\hline Sex & 0.059 & 0.059 & -0.009 & -0.004 \\
Age & -0.090 & -0.034 & 0.067 & 0.085 \\
ED & -0.125 & -0.061 & 0.089 & 0.108 \\
WYCC & 0.037 & 0.074 & 0.086 & 0.105 \\
SL & - & $0.427^{* * *}$ & - & $0.193^{* *}$ \\
JA & - & - & $0.504^{* * *}$ & $0.424^{* * *}$ \\
$\mathrm{R}^{2}$ & 0.023 & 0.195 & 0.262 & 0.291 \\
Adjusted $\mathrm{R}^{2}$ & 0.005 & 0.177 & 0.245 & 0.272 \\
$\Delta \mathrm{R}^{2}$ & 0.023 & 0.173 & 0.248 & 0.145 \\
$\mathrm{~F}$ & 1.282 & $10.730^{* * *}$ & $15.701^{* * *}$ & $15.064^{* * *}$ \\
$\Delta \mathrm{F}$ & 1.282 & $47.452^{* * *}$ & $74.368^{* * *}$ & $44.918^{* * *}$ \\
\hline
\end{tabular}

Table 4. Mediating effects of LMX $(\mathrm{N}=227)$.

\begin{tabular}{ccccc}
\hline \multirow{2}{*}{ Variable } & \multicolumn{2}{c}{ LMX } & \multicolumn{2}{c}{ TMP } \\
\cline { 2 - 5 } & Model 9 & Model 10 & Model 11 & Model 12 \\
\hline Sex & 0.064 & 0.065 & -0.014 & -0.010 \\
Age & -0.117 & -0.019 & 0.174 & 0.178 \\
ED & -0.017 & 0.095 & 0.052 & 0.063 \\
WYCC & 0.034 & 0.098 & 0.001 & 0.010 \\
SL & - & $0.749^{* * *}$ & - & 0.081 \\
LMX & - & - & $0.405^{* * *}$ & $0.347^{* * *}$ \\
R & 0.016 & -0.002 & 0.180 & 0.183 \\
Adjusted $\mathrm{R}^{2}$ & 0.548 & 0.538 & 0.162 & 0.161 \\
$\Delta \mathrm{R}^{2}$ & 0.016 & 0.533 & 0.161 & 0.054 \\
F & 0.884 & $53.654^{* * *}$ & $9.707^{* * *}$ & $8.208^{* * *}$ \\
$\Delta \mathrm{F}$ & 0.884 & $260.598^{* * *}$ & $43.519^{* * *}$ & $14.618^{* * *}$ \\
\hline
\end{tabular}

Table 5. Mediating effects of RBSE $(\mathrm{N}=227)$.

\begin{tabular}{ccccccc}
\hline \multirow{2}{*}{ Variable } & \multicolumn{2}{c}{ RBSE } & \multicolumn{2}{c}{ ITP } & \multicolumn{2}{c}{ TMP } \\
\cline { 2 - 7 } & Model 13 & Model 14 & Model 15 & Model 16 & Model 17 & Model 18 \\
\hline Sex & -0.039 & -0.039 & 0.046 & 0.038 & 0.038 & 0.038 \\
Age & -0.012 & 0.047 & 0.029 & $0.134^{*}$ & $0.134^{*}$ & $0.140^{*}$ \\
ED & 0.038 & 0.105 & 0.002 & 0.019 & 0.019 & 0.027 \\
WYCC & 0.164 & $0.203^{* *}$ & -0.002 & -0.095 & -0.095 & -0.088 \\
SL & - & $0.449^{* * *}$ & - & - & - & 0.049 \\
\hline
\end{tabular}


Continued

\begin{tabular}{ccccccc}
\hline RBSE & - & - & $0.649^{* * *}$ & $0.672^{* * *}$ & $0.672^{* * *}$ & $0.650^{* * *}$ \\
$\mathrm{R}^{2}$ & 0.027 & 0.218 & 0.423 & 0.458 & 0.458 & 0.459 \\
Adjusted $\mathrm{R}^{2}$ & 0.010 & 0.201 & 0.410 & 0.445 & 0.445 & 0.445 \\
$\Delta \mathrm{R}^{2}$ & 0.027 & 0.191 & 0.049 & 0.439 & 0.439 & 0.331 \\
$\mathrm{~F}$ & 1.549 & $12.342^{* * *}$ & $32.444^{* * *}$ & $37.729^{* * *}$ & $37.729^{* * *}$ & $31.150^{* * *}$ \\
$\Delta \mathrm{F}$ & 1.549 & $54.034^{* * *}$ & $156.927^{* * *}$ & $178.814^{* * *}$ & $178.814^{* * *}$ & $134.568^{* * *}$
\end{tabular}

\subsection{Comparison of Mediating Effects}

This research used Bootstrapping (with a sample of 1000) to further verify the significance of three mediating effects and compare the differences in the mediating mechanisms of employees' proactive behaviors directed to different targets.

According to the judgment criterion that whether the confidence interval contains zero and the results shown in Table 6, hypotheses 3 and 5 were supported. In addition, from the perspective of mediating effects' comparison, the coefficient of indirect effects for job autonomy and role breadth self-efficacy were higher than leader-member exchange. Moreover, the mediating effect of leader-member exchange on the relationship between servant leadership and individual task proactivity was not significant. The reason may be that individual task proactivity emphasizes the employees' attention to their own work, so the needs for support from leaders and team members is less than team member proactivity which is aimed to change the team affairs, as a result, the influence of leader-member exchange was relatively small.

According to the results shown in Table 7, hypotheses 4 and 6 were supported. What's more, from the perspective of mediating effects' comparison, the coefficient of indirect effects for leader-member exchange and role breadth self-efficacy were higher than job autonomy. Moreover, the mediating effect of job autonomy on the relationship between servant leadership and team member proactivity was not significant. It indicates that as the risk of proactive behaviors increase, employees will consider more about the needs for relatedness when they choose to be initiative, especially the relationship with leaders and the support that can be obtained from leaders and teams. Employees establish a good relationship with leaders and receive support from the team through leaders' support, which helps to reduce the risk perception and enhance the feasibility perception for team member proactivity.

\section{Conclusion and Discussion}

First of all, we found that servant leadership had positive effects on individual task proactivity and team member proactivity. What's more, the regression coefficient of servant leadership on employees' individual task proactivity $(\beta=0.374$, $p<0.001)$ was higher than the regression coefficient of servant leadership on team member proactivity $(\beta=0.341, p<0.001)$. This indicates that employees' 
Table 6. Mediating effects of SL on ITP $(\mathrm{N}=227)$.

\begin{tabular}{ccccc}
\hline \multirow{2}{*}{ Variable } & Indirect Effect & SE & \multicolumn{2}{c}{ Bootstrapping BC 95\% CI } \\
\cline { 4 - 5 } & & & Lower & Upper \\
\hline JA & 0.068 & 0.030 & 0.024 & 0.147 \\
LMX & 0.007 & 0.058 & -0.097 & 0.124 \\
RBSE & 0.188 & 0.039 & 0.123 & 0.282 \\
TOTAL & 0.263 & 0.071 & 0.140 & 0.425 \\
\hline
\end{tabular}

BC, Bias Corrected; 1000 Bootstrap Sample; Model 4. The same as the following table.

Table 7. Mediating effects of SL on TMP $(\mathrm{N}=227)$.

\begin{tabular}{ccccc}
\hline \multirow{2}{*}{ Variable } & Indirect Effect & SE & \multicolumn{2}{c}{ Bootstrapping BC 95\% CI } \\
\cline { 4 - 5 } & & & Lower & Upper \\
\hline JA & 0.018 & 0.030 & -0.029 & 0.091 \\
LMX & 0.076 & 0.071 & 0.070 & 0.118 \\
RBSE & 0.214 & 0.056 & 0.218 & 0.449 \\
TOTAL & 0.308 & 0.086 & 0.139 & 0.491 \\
\hline
\end{tabular}

team member proactivity is relatively less than individual task proactivity in the same servant leadership context. As mentioned above, employees' team member proactivity involves the impact and change on other team members, which needs more competence and to take greater risk, resulting in relatively less team member proactivity in workplace. Apart from this, we also found that the relationship between servant leadership and individual task proactivity was mediated by job autonomy and role breadth self-efficacy, and the mediating effect of leader-member exchange was not significant. While leader-member exchange and role breadth self-efficacy mediated the influence of servant leadership on team member proactivity, and the mediating effect of job autonomy was not significant. It indicates that there are certain differences in the mediating mechanisms of employees' proactive behaviors directed to different targets. Besides, to satisfy the needs for autonomy and competence is important for inspiring employees to show more proactive behaviors in their work, while to satisfy the needs for relatedness and competence is vital for promoting employees to show more proactivity in the team affairs.

Overall, this study has contributed to the literature in two aspects. On one hand, the research of relationship between servant leadership and proactive behaviors integrates several leadership factors' impact on employees' proactive behaviors and fills the blank of the research on relationship between them. It enriches and develops related theories of proactive behaviors' influencing factors. On the other hand, this study uses cognitive evaluation theory to integrate the mechanisms that motivate employees' proactive behaviors, and species the different psychological processes that servant leadership promotes employees' 
proactive behaviors directed to different targets.

Furthermore, this research also provides important practical implications. Leaders can inspire employees' individual task proactivity and team member proactivity by demonstrating more servant leadership's traits like empowerment, helping subordinates grow and succeed, putting subordinates first, behaving ethically, emotional healing, creating a collectivist atmosphere in the team and so on. Moreover, leaders should treat differently to employees' proactive behaviors directed to different targets, so as to motivate these behaviors effectively. First of all, no matter what kind of proactive behaviors, satisfying the needs for competence is necessary, such as providing employees with space and opportunities for development, encouraging employees to participate in team decision-making, and actively supporting the employees during their work. Secondly, if leaders want employees to exhibit more individual task proactivity, they should focus on meeting employees' needs for autonomy, such as authorization, giving employees responsibility, and encouraging employees to handle important work decisions on their own. At the same time, if leaders want employees to exhibit more team member proactivity, they should focus on meeting employees' needs for relatedness, such as establishing high quality relationship with employees, trusting and respecting employees, and being able to listen to employees' ideas about team work. In addition, by promoting a team culture of help each other, employees' team member proactivity can receive more support and assistance from team members.

There are some limitations in this research. In terms of research design, all variables were collected at the same time, and the following studies can adopt a rigorous three-point longitudinal study design. In addition, the samples only came from two companies and two regions, making the scope of data collection relatively small, which limits the universality of research conclusions. Lastly, the amount of research data can be further increased. In terms of variables, the control variables can be further enriched in the future, which is conducive to the in-depth study of the influence of control variables on the relationships among variables in the research model. Moreover, the effects of servant leadership may be influenced by organizational culture, employees' personal characteristics, future research may consider those moderator variables. Besides, under the cognitive evaluation theory, it is also possible to consider more variables which may have impact on the psychological needs for autonomy, competence, and relatedness, and discuss their mediating effects.

\section{References}

Bindl, U. K., \& Parker, S. K. (2009). Investigating Self-Regulatory Elements of Proactivity at Work. Working Paper, Sheffield: Institute of Work Psychology, University of Sheffield.

Botero, I. C., \& Dyne, L. V. (2009). Employee Voice Behavior Interactive Effects of LMX and Power Distance in the United States and Colombia. Management Communication Quarterly, 23, 84-104. https://doi.org/10.1177/0893318909335415 
Chen, Z., Lam, W., \& Zhong, J. A. (2007). Leader-Member Exchange and Member Performance: A New Look at Individual-Level Negative Feedback-Seeking Behavior and Team-Level Empowerment Climate. Journal of Applied Psychology, 92, 202-212. https://doi.org/10.1037/0021-9010.92.1.202

Day, D. V., \& Crain, E. C. (1992). The Role of Affect and Ability in Initial Exchange Quality Perceptions. Group \& Organization Management, 17, 380-397.

https://doi.org/10.1177/1059601192174005

Deci, E. L., \& Ryan, R. M. (2000). The "What" and "Why" of Goal Pursuits: Human Needs and the Self-Determination of Behavior. Psychological Inquiry, 11, 227-268. https://doi.org/10.1207/S15327965PLI1104_01

Dienesch, R. M., \& Liden, R. C. (1986). Leader-Member Exchange Model of Leadership: A Critique and Further Development. Academy of Management Review, 11, 618-634. https://doi.org/10.5465/amr.1986.4306242

Graen, G. B., \& Uhlbien, M. (1995). Relationship-Based Approach to Leadership: Development of Leader-Member Exchange (LMX) Theory of Leadership over 25 Years: Applying a Multi-Level Multi-Domain Perspective. Leadership Quarterly, 6, 219-247. https://doi.org/10.1016/1048-9843(95)90036-5

Griffin, M. A., Neal, A., \& Parker, S. K. (2007). A New Model of Work Role Performance: Positive Behavior in Uncertain and Interdependent Contexts. Academy of Management Journal, 50, 327-347. https://doi.org/10.5465/amj.2007.24634438

Hackman, J. R., \& Oldham, G. R. (1976). Motivation through the Design of Work: Test of a Theory. Organizational Behavior \& Human Performance, 16, 250-279. https://doi.org/10.1016/0030-5073(76)90016-7

Ilies, R., \& Judge, T. A. (2005). Goal Regulation across Time: The Effects of Feedback and Affect. Journal of Applied Psychology, 90, 453-467. https://doi.org/10.1037/0021-9010.90.3.453

Liden, R. C., Wayne, S. J., Liao, C., \& Meuser, J. D. (2014). Servant Leadership and Serving Culture: Influence on Individual and Unit Performance. Academy of Management Journal, 57, 1434-1452. https://doi.org/10.5465/amj.2013.0034

Liden, R. C., Wayne, S. J., Zhao, H., \& Henderson, D. (2008). Servant Leadership: Development of a Multidimensional Measure and Multi-Level Assessment. Leadership Quarterly, 19, 161-177. https://doi.org/10.1016/j.leaqua.2008.01.006

Oettingen, G., Mayer, D., Thorpe, J. S., Janetzke, H., \& Lorenz, S. (2005). Turning Fantasies about Positive and Negative Futures into Self-Improvement Goals. Motivation \& Emotion, 29, 236-266. https://doi.org/10.1007/s11031-006-9016-y

Parker, S. K. (1998). Enhancing Role Breadth Self-Efficacy: The Roles of Job Enrichment and Other Organizational Interventions. Journal of Applied Psychology, 83, 835. https://doi.org/10.1037/0021-9010.83.6.835

Parker, S. K., Bindl, U. K., \& Strauss, K. (2010). Making Things Happen: A Model of Proactive Motivation. Journal of Management, 36, 827-856.

https://doi.org/10.1177/0149206310363732

Parker, S. K., Wall, T. D., \& Jackson, P. R. (1997). “That's Not My Job”: Developing Flexible Employee Work Orientations. Academy of Management Journal, 40, 899-929. https://doi.org/10.5465/256952

Reinke, S. J. (2004). Service before Self: Towards a Theory of Servant-Leadership. Global Virtue Ethics Review, 5, 30-57.

Ryan, R. M., \& Deci, E. L. (2000). Self-Determination Theory and the Facilitation of Intrinsic Motivation, Social Development and Well-Being. American Psychologist, 55, 
68-78. https://doi.org/10.1037/0003-066X.55.1.68

Salancik, G. R., \& Pfeffer, J. (1978). Uncertainty, Secrecy, and the Choice of Similar Others. Social Psychology, 41, 246-255. https://doi.org/10.2307/3033561

Salanova, M., \& Schaufeli, W. B. (2008). A Cross-National Study of Work Engagement as a Mediator between Job Resources and Proactive Behaviour. International Journal of Human Resource Management, 19, 116-131. https://doi.org/10.1080/09585190701763982

Van Dyne, L., Kamdar, D., \& Joireman, J. (2008). In-Role Perceptions Buffer the Negative Impact of Low LMX on Helping and Enhance the Positive Impact of High LMX on Voice. Journal of Applied Psychology, 93, 1195-1207.

https://doi.org/10.1037/0021-9010.93.6.1195

Walumbwa, F. O., Hartnell, C. A., \& Oke, A. (2010). Servant Leadership, Procedural Justice Climate, Service Climate, Employee Attitudes, and Organizational Citizenship Behavior: A Cross-Level Investigation. Journal of Applied Psychology, 95, 517-529.

https://doi.org/10.1037/a0018867 